\title{
Recent progress in the development of advanced biofuel 5-ethoxymethylfurfural
}

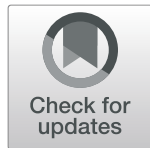

\author{
Binglin Chen ${ }^{1}$, Guihua Yan ${ }^{1}$, Gaofeng Chen ${ }^{1}$, Yunchao Feng ${ }^{1}$, Xianhai Zeng ${ }^{1,2^{*}}$, Yong Sun ${ }^{1,2}$, Xing Tang ${ }^{1,2}$, \\ Tingzhou Lei ${ }^{3}$ and Lu Lin ${ }^{1,2}$
}

\begin{abstract}
Biomass-derived 5-ethoxymethylfurfural (EMF) with excellent energy density and satisfactory combustion performance holds great promise to meet the growing demands for transportation fuels and fuel additives to a certain extent. In this review, we summarized the relative merits of the EMF preparation from different feedstocks, such as platform chemicals, biomass sugars and lignocellulosic biomass. Advances for EMF synthesis over homogeneous (i.e. inorganic acids and soluble metal salts), heterogeneous catalysts (i.e. zeolites, heteropolyacidbased hybrids, sulfonic acid-functionalized catalysts, and others) or mixed-acid catalysts were performed as well. Additionally, the emerging development for the EMF production was also evaluated in terms of the different solvents system (i.e. single-phase solvents, biphasic solvents, ionic liquids, and deep eutectic solvents). It is concluded with current challenges and prospects for advanced biofuel EMF preparation in the future.
\end{abstract}

Keywords: Biofuel, 5-ethoxymethylfurfural, Feedstocks, Homogeneous, Heterogeneous, Mixed acid, Solvent

\section{Introduction}

It is urgent to convert renewable biomass resources into advanced biofuels, and platform chemicals, such as polyhydric alcohol, furan compounds, short-chain alkanes, organic acids, and their esters derivatives [1-4]. Among these biofuels, 5-ethoxymethylfurfural (EMF), as a promising transportation fuel and fuel additive, has been in a center of attention [5-7]. The energy density of EMF $(30.3 \mathrm{MJ} / \mathrm{L})$ is closed to that of gasoline $(31.3 \mathrm{MJ} / \mathrm{L})$ and diesel $(33.6 \mathrm{MJ} / \mathrm{L})$, and higher than that of ethanol $(23.5$ $\mathrm{MJ} / \mathrm{L})[8,9]$. In addition, EMF as advanced biofuel can reduce the environmental pollution profiting from its high oxidation stability, accompanied by the reduction of soot emissions, sulfur oxides and nitrogen oxides [10,11].

At present, EMF is usually synthesized from biomass sugars (i.e. glucose, fructose, inulin) over the acid catalyst

\footnotetext{
* Correspondence: xianhai.zeng@xmu.edu.cn

${ }^{1}$ College of Energy, Xiamen University, Xiamen 361102, China

${ }^{2}$ Fujian Engineering and Research Centre of Clean and High-valued

Technologies for Biomass, Xiamen Key Laboratory of Clean and High-valued Utilization for Biomass, Xiamen 361102, China

Full list of author information is available at the end of the article
}

in ethanol. In contrast with traditional hydrolysis, the most remarkable advantage in ethanol system is that it could minimize the wastewater treatment and discharge. Meanwhile, unreacted ethanol can be easily recovered, which accords with sustainable development. What's more, the ethanol reactant is more conducive to the production of active groups in glycosyl and the reduction of side reactions. As shown in Fig. 1, the ethanolysis of biomass to EMF is a continuous multi-step reaction [12]. In brief, cellulose was firstly hydrolyzed to glucose in the presence of acidic catalysts, and then divided into two ways: (1) glucose was isomerized to fructose through Lewis acid sites, and then EMF was produced with dehydration of fructose followed by in-situ etherification of 5hydroxymethylfurfural (HMF) in ethanol. (2) Glucose was easily converted into ethyl glucoside (EG) through Brønsted acid sites and then formed EMF. Although the preparation pathway undergoes a multi-step intermediate process, the reaction can be carried out continuously in the same reactor with the simple process and controllable conditions. Therefore, the preparation pathway is also 


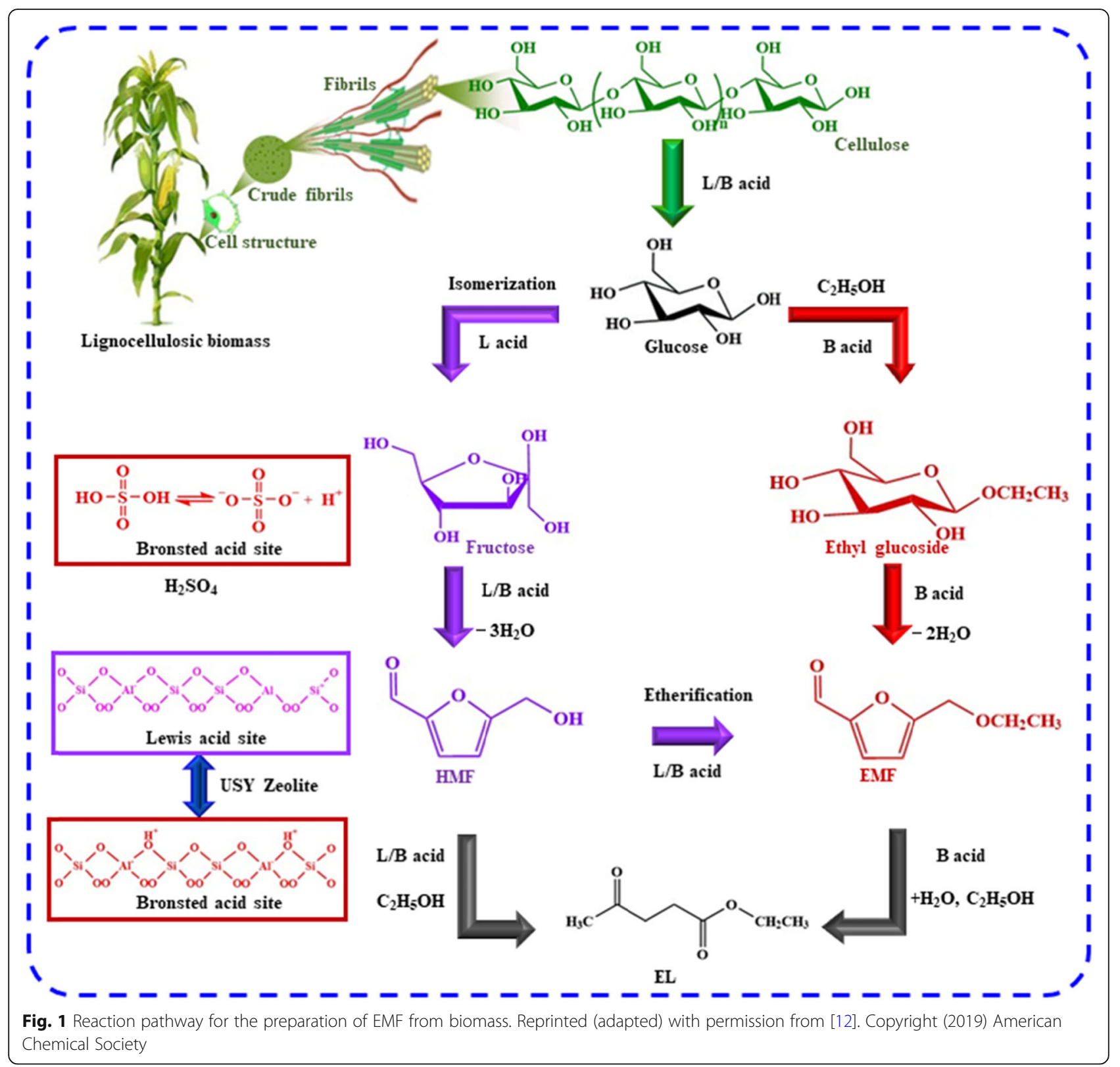

called "one-pot" reaction. Given the above advantages, direct ethanolysis of biomass to prepare EMF is considered as a potential approach for biomass development and utilization.

Here, the progress of EMF preparation had been deeply analyzed in the sections of feedstocks, catalysts system and solvents. More importantly, the current challenges and future perspectives have also been prospected.

\section{Feedstocks}

The feedstocks of EMF preparation were mainly divided into three categories: (1) the platform chemicals were directly etherified to prepare EMF in acidic conditions, such as HMF, 5-chloromethylfurfural (CMF) and 5- bromomethylfurfural (BMF). (2) The biomass sugars (i.e. glucose), were sequentially subjected to the steps of isomerization, dehydration, and etherification to prepare EMF. (3) The lignocellulosic biomass was directly transformed into EMF. The summarization was listed in Table 1 and Fig.2.

HMF, as the most common platform chemical, has a furan ring, a hydroxymethyl and an aldehyde group, which made it has many active chemical properties. Therefore, many derivatives could be obtained by condensation, oxidation, hydrogenation, or by directly etherification in the ethanol system [31, 32]. Much research on the etherification of HMF to EMF has been reported, and the results almost had superior conversion and 
Table 1 Valorization of various biomass into EMF

\begin{tabular}{|c|c|c|c|c|c|c|c|}
\hline Entry & Feedstock & Catalyst & Solvent & Temp. $/{ }^{\circ} \mathrm{C}$ & Time/h & Yield/\% & Ref. \\
\hline 1 & HMF & $30 \% \mathrm{TaTPA} / \mathrm{SnO}_{2}$ & $\mathrm{EtOH}^{\mathrm{a}}$ & 120 & 0.75 & 90.2 & $\overline{[13]}$ \\
\hline 2 & Fructose & $30 \% \mathrm{TaTPA} / \mathrm{SnO}_{2}$ & $\mathrm{EtOH}$ & 120 & 8 & 68 & [13] \\
\hline 3 & HMF & {$[\mathrm{MIMBS}]_{3} \mathrm{PW}_{12} \mathrm{O}_{40}$} & $\mathrm{EtOH}$ & 70 & 24 & 90.7 & [14] \\
\hline 4 & HMF & $\mathrm{Fe}_{3} \mathrm{O}_{4} @ \mathrm{SiO}_{2}-\mathrm{HPW}$ & $\mathrm{EtOH}$ & 100 & 11 & 84 & [15] \\
\hline 5 & Fructose & $\mathrm{Fe}_{3} \mathrm{O}_{4} @ \mathrm{SiO}_{2}-\mathrm{HPW}$ & $\mathrm{EtOH}$ & 100 & 24 & 55 & [15] \\
\hline 6 & HMF & $\mathrm{C} / \mathrm{SBA}(45)$ & $\mathrm{EtOH}$ & 110 & 4 & 80 & [16] \\
\hline 7 & HMF & C/MCF(63) & $\mathrm{EtOH}$ & 110 & 4 & 78 & [16] \\
\hline 8 & HMF & K-10 clay-Al & $\mathrm{EtOH}$ & 100 & 8 & 89.5 & [17] \\
\hline 9 & HMF & $\mathrm{Cs}_{2} \mathrm{STA}$ & $\mathrm{EtOH}$ & 120 & 2.5 & 91 & [18] \\
\hline 10 & Fructose & Poly (VMPS)-PW & $\mathrm{EtOH}$ & 110 & 10 & 72.5 & [19] \\
\hline 11 & Fructose & {$\left[\mathrm{C}_{3} \mathrm{~N}\right]\left[\mathrm{SO}_{3} \mathrm{CF}_{3}\right]-\mathrm{HCSs}-1$} & $\mathrm{EtOH}$ & 140 & 2 & 67.2 & [20] \\
\hline 12 & Fructose & $\mathrm{HReO}_{4}(10 \mathrm{~mol} \%)$ & $\mathrm{EtOH}$ & 140 & 1 & 63 & [21] \\
\hline 13 & Fructose & $\mathrm{HReO}_{4}(10$ mol\%) & $\mathrm{EtOH} / \mathrm{THF}^{\mathrm{b}}$ & 140 & 1 & 73 & [21] \\
\hline 14 & Inulin & $\mathrm{HReO}_{4}(10 \mathrm{~mol} \%)$ & $\mathrm{EtOH} / \mathrm{THF}$ & 140 & 1 & 51 & [21] \\
\hline 15 & Sucrose & $\mathrm{HReO}_{4}(10 \mathrm{~mol} \%)$ & $\mathrm{EtOH} / \mathrm{THF}$ & 140 & 1 & 36 & [21] \\
\hline 16 & $\mathrm{HMF}$ & S-PANI & $\mathrm{EtOH}$ & 90 & 6 & 83.8 & [22] \\
\hline 17 & HMF & S-PANI-FeVO $4(11)$ & $\mathrm{EtOH}$ & 90 & 6 & 80 & [22] \\
\hline 18 & Sucrose & S-PANI-FeVO ${ }_{4}(11)$ & $\mathrm{EtOH}$ & 90 & 24 & 57.2 & [22] \\
\hline 19 & Fructose & S-PANI-FeVO 4 (11) & $\mathrm{EtOH}$ & 90 & 24 & 72.5 & [22] \\
\hline 20 & Fructose & $\mathrm{PSDVB}_{-} \mathrm{SO}_{3} \mathrm{H}$ & $\mathrm{EtOH}$ & 120 & 2 & 67.5 & [23] \\
\hline 21 & Sucrose & $\mathrm{PSDVB}_{-} \mathrm{SO}_{3} \mathrm{H}$ & $\mathrm{EtOH}$ & 120 & 2 & 31.1 & [23] \\
\hline 22 & Fructose & $\mathrm{MCC}-\mathrm{SO}_{3} \mathrm{H}$ & $\mathrm{EtOH}$ & 120 & 16 & 63.2 & [24] \\
\hline 23 & Inulin & $\mathrm{MCC}-\mathrm{SO}_{3} \mathrm{H}$ & $\mathrm{EtOH}$ & 120 & 16 & 51.3 & [24] \\
\hline 24 & Sucrose & $\mathrm{MCC}-\mathrm{SO}_{3} \mathrm{H}$ & $\mathrm{EtOH}$ & 120 & 16 & 32.5 & [24] \\
\hline 25 & Glucose & $\mathrm{MCC}-\mathrm{SO}_{3} \mathrm{H}$ & $\mathrm{EtOH}$ & 120 & 16 & $86.5^{c}$ & [24] \\
\hline 26 & Glucose & Sn-BEA and Amberlyst-13 & $\mathrm{EtOH}$ & 90 & 24 & 31 & [25] \\
\hline 27 & Fructose & $\mathrm{H}_{3} \mathrm{PW}_{12} \mathrm{O}_{40}$ & $\mathrm{EtOH} / \mathrm{THF}(5: 3)$ & 130 & 0.5 & 76 & [26] \\
\hline 28 & Fructose & $\mathrm{H}_{3} \mathrm{PW}_{12} \mathrm{O}_{40}$ & $\mathrm{EtOH}$ & 130 & 0.5 & 65 & [26] \\
\hline 29 & Sucrose & $\mathrm{H}_{3} \mathrm{PW}_{12} \mathrm{O}_{40}$ & $\mathrm{EtOH} / \mathrm{THF}(5: 3)$ & 130 & 0.5 & 33 & [26] \\
\hline 30 & Inulin & $\mathrm{H}_{3} \mathrm{PW}_{12} \mathrm{O}_{40}$ & $\mathrm{EtOH} / \mathrm{THF}(5: 3)$ & 130 & 0.5 & 62 & [26] \\
\hline 31 & Fructose & MIL-101-SO ${ }_{3} \mathrm{H}(100)$ & $\mathrm{EtOH} / \mathrm{THF}(5: 4)$ & 130 & 15 & 67.7 & [27] \\
\hline 32 & Inulin & MIL-101-SO ${ }_{3} \mathrm{H}(100)$ & $\mathrm{EtOH} / \mathrm{THF}(5: 4)$ & 130 & 15 & 54.2 & [27] \\
\hline 33 & Cellulose & $\mathrm{H}_{2} \mathrm{SO}_{4}$ & $\mathrm{EtOH}$ & 200 & 1.25 & 14.93 & [28] \\
\hline 34 & Corn stover & $\mathrm{USY} / \mathrm{H}_{2} \mathrm{SO}_{4}$ & $\mathrm{EtOH}$ & 210 & 2.05 & 23.9 & [12] \\
\hline 35 & Cassava & $\mathrm{NiSO}_{4}$ & $\mathrm{EtOH}$ & 200 & 2 & 11.4 & [29] \\
\hline 36 & Bagasse & $\mathrm{Zr}(\mathrm{O}) \mathrm{Cl}_{2} / \mathrm{CrCl}_{3}$ & $\mathrm{EtOH} /[\mathrm{Bmim}] \mathrm{Cl}$ & 120 & 15 & $21.6^{d}$ & [30] \\
\hline
\end{tabular}

${ }^{\mathrm{a}} \mathrm{EtOH}$ is ethanol; ${ }^{\mathrm{b}}$ THF is tetrahydrofuran; ${ }^{\mathrm{c}}$ The yield is EG yield; ${ }^{\mathrm{d}}$ The yield is mass yield

selectivity in various reaction processes [13-18]. Kumari et al. [13] conducted HMF etherification over Ta exchanged tungstophosphoric acid with $\mathrm{SnO}_{2}$ support as the catalyst, the EMF yield was $90.2 \%$. A $91 \%$ of EMF yield was reached from HMF used $\mathrm{Cs}_{2} \mathrm{STA}$ as the catalyst in ethanol by Raveendra et al. [18] as well. However, the industrial production of EMF was limited by the high price of HMF.
Biomass sugars, as raw materials, were usually divided into fructose-based carbohydrates and glucose-based carbohydrates [33]. According to previous study, the EMF yield could go as high as 60\% 90\% when fructose was used as substrate [19-21], while it was 30\% 60\% with sucrose [22-24]. However, the EMF yield was almost as low as $40 \%$ due to the speed limit of glucose isomerization to fructose [25]. Furthermore, the yields of EMF from inulin 


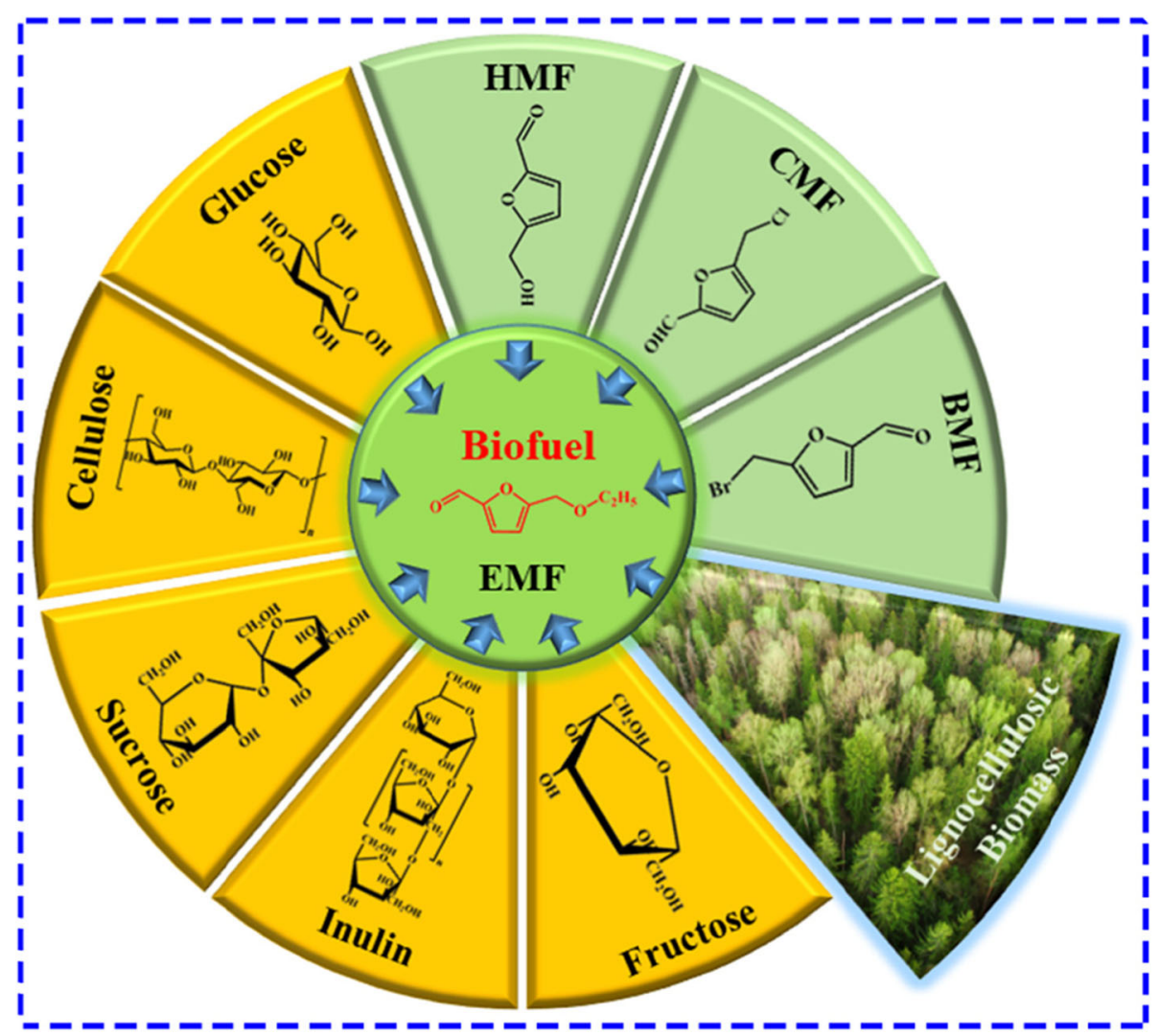

Fig. 2 Preparation of EMF from various feedstocks

were slightly lower compared to the case that fructose was used as feed $[26,27]$. This was because that one unit of inulin consists of one unit of glucose and 1 59 units of fructose. Cellulose is the most widely distributed and abundant polysaccharide in nature [34]. Presently, there are two processes for preparing EMF from cellulose. Cellulose was directly converted into BMF in dichloroethane medium and then EMF with a yield of $40 \%$ could be obtained after reflux, evaporation, extraction, and washing processes. Although highly considerable yield could be reached, long reaction time $(4 \mathrm{~h})$ and complexed subsequent extraction process still existed in this process [35]. In the other case, low sulphuric acid acted as the homogeneous catalyst for the synthesis of EMF by one pot with the simple preparation process and short reaction time $(1.25 \mathrm{~h})$, resulting in a low yield $(14.93 \%)$ [28]. Therefore, when biomass sugars were used as raw materials by one pot method, the general trend of EMF yield showed as follows: fructose $>$ inulin $>$ sucrose $>$ glucose $>$ cellulose.

A large amount of biomass waste was produced in the world every year, which would improve its utilization rate if it was used reasonably. Corn stover was employed for the synthesis of EMF, and the yield could reach $23.9 \%$ over mixed acid catalyst by author's group [12]. Tian et al. [29] prepared EMF from waste cassava by $\mathrm{NiSO}_{4}$ with a yield of $11.4 \%$. In addition, $21.6 \%$ mass yield of EMF could be obtained from bagasse with $\mathrm{Zr}(\mathrm{O}) \mathrm{Cl}_{2} / \mathrm{CrCl}_{3}$ after $15 \mathrm{~h}$ [30]. In general, EMF yield was very low due to the complex of biomass structure. Therefore, in order to achieve the goal of sustainable development, the inexpensive biomass resources should be focused on the development of direct transformation and synthesis technology of EMF as well as hierarchical utilization of biomass resources.

\section{Catalytic system}

Catalysts played a crucial role in the conversion of biomass to EMF, which mainly promoted the isomerization of glucose and assisted the reaction of fructose to EMF [36]. By now, the reported catalysts for the synthesis of EMF mainly included inorganic liquid acids, metal salts, molecular sieves, sulfonated solid acids, functionalized ionic liquids, heteropoly acids, etc. The catalytic system would be divided into homogeneous catalytic system, heterogeneous catalytic system, and mixed-acid catalytic system, according to the reaction characteristics of the synthesis of EMF.

\section{Homogeneous catalytic system}

Homogeneous catalysts are attractive choices because of their uniform distribution of catalytic sites in solvents, which could adequately mix reaction substrates for catalytic 
reactions [37]. Homogeneous catalysts used for the preparation of EMF from biomass had been summarized and listed in Table 2, within mainly inorganic acids and soluble metal salts.

In general, $\mathrm{H}_{2} \mathrm{SO}_{4}$ [38] and $\mathrm{HCl}$ [39] were employed for the preparation of EMF from fructose, the results indicated that the yield of EMF was much higher with $\mathrm{H}_{2} \mathrm{SO}_{4}(70 \%)$ than that of with $\mathrm{HCl}(40 \%)$. In addition, the amount of HMF was almost not detected with $\mathrm{H}_{2} \mathrm{SO}_{4}$ as the catalyst while that of was significant (24\%) with $\mathrm{HCl}$ as the catalyst. However, it was also noted that the longer reaction time $(24 \mathrm{~h})$ was needed with sulfuric acid as the catalyst, while only $2 \mathrm{~h}$ of the reaction was performed in the case of $\mathrm{HCl}$. The effects of $\mathrm{H}_{2} \mathrm{SO}_{4}$ and $\mathrm{H}_{3} \mathrm{PO}_{4}$ on $\mathrm{HMF}$ etherification were investigated as well by Che et al. [40], and only $1.7 \%$ EMF yield was detected in the presence of $\mathrm{H}_{3} \mathrm{PO}_{4}$ when the yield of EMF was up to $79 \%$ with $\mathrm{H}_{2} \mathrm{SO}_{4}$ as the catalyst. They claimed that strong acids could provide enough acidic sites for EMF production. Flannelly et al. [41] also found that $\mathrm{H}_{2} \mathrm{SO}_{4}$ had relatively high catalytic activity and the mass yield was $63 \%$ from fructose. However, the equipment was seriously corroded due to the $\mathrm{H}_{2} \mathrm{SO}_{4}$ used as the catalyst. To overcome this problem, extremely low sulphuric acid (0.1 wt.\% $\mathrm{H}_{2} \mathrm{SO}_{4}$ ) was implemented as the catalyst for the synthesis of EMF from fructose by Xu et al. [42], and the EMF yield was $66 \%$ at $120^{\circ} \mathrm{C}$. Although the yield was decreased, it could effectively reduce the negative impact on equipment corrosion and environment. Sulfuric acid, as a representative of inorganic acids, has great catalytic activity and is a commercial product. However, the higher concentration of $\mathrm{H}_{2} \mathrm{SO}_{4}$ would lead to the formation of humins and the tedious post-process while the lower concentration of $\mathrm{H}_{2} \mathrm{SO}_{4}$ needs higher temperature and pressure to reach a better catalytic activity.

Metal chloride has been in the spotlight as a commercially available Lewis acid for the transformation of hexoses. Various metal salts were investigated for the production of EMF with fructose as feed by Liu et al.

Table 2 Preparation of EMF from biomass by homogeneous catalysts

\begin{tabular}{|c|c|c|c|c|c|c|c|}
\hline Entry & Feedstock & Catalyst & Solvent & Temp. $/{ }^{\circ} \mathrm{C}$ & Time/h & Yield/\% & Ref. \\
\hline 1 & Fructose & $\mathrm{H}_{2} \mathrm{SO}_{4}(10 \mathrm{~mol} \%)$ & $\mathrm{EtOH}$ & 100 & 24 & 70 & [38] \\
\hline 2 & HMF & $\mathrm{H}_{2} \mathrm{SO}_{4}(5 \mathrm{~mol} \%)$ & $\mathrm{EtOH}$ & 75 & 24 & 81 & [38] \\
\hline 3 & Fructose & $\mathrm{HCl}(5$ mol\%) & $\mathrm{EtOH}$ & 120 & 2 & 40 & [39] \\
\hline 4 & HMF & $\mathrm{H}_{3} \mathrm{PO}_{4}$ & $\mathrm{EtOH}$ & 90 & 2 & 1.7 & [40] \\
\hline 5 & HMF & $\mathrm{H}_{2} \mathrm{SO}_{4}$ & $\mathrm{EtOH}$ & 90 & 2 & 79 & [40] \\
\hline 6 & Fructose & $\mathrm{H}_{2} \mathrm{SO}_{4}$ & $\mathrm{EtOH}$ & 100 & 24 & $63^{\mathrm{a}}$ & [41] \\
\hline 7 & Fructose & $\mathrm{H}_{2} \mathrm{SO}_{4}(0.1$ wt.\%) & $\mathrm{EtOH} / \mathrm{n}$-hexane & 120 & 3 & 66 & [42] \\
\hline 8 & Fructose & $\mathrm{CuCl}_{2} \cdot 2 \mathrm{H}_{2} \mathrm{O}$ & $\mathrm{EtOH}$ & 100 & 12 & 12 & [43] \\
\hline 9 & Fructose & $\mathrm{NiCl}_{2} \cdot 6 \mathrm{H}_{2} \mathrm{O}$ & $\mathrm{EtOH}$ & 100 & 12 & 5 & [43] \\
\hline 10 & Fructose & $\mathrm{SnCl}_{4} \cdot 5 \mathrm{H}_{2} \mathrm{O}$ & $\mathrm{EtOH}$ & 100 & 12 & 23 & [43] \\
\hline 11 & Fructose & $\mathrm{FeCl}_{3}$ & $\mathrm{EtOH}$ & 100 & 12 & 28 & [43] \\
\hline 12 & Fructose & $\mathrm{CrCl}_{3} \cdot 6 \mathrm{H}_{2} \mathrm{O}$ & $\mathrm{EtOH}$ & 100 & 12 & 33 & [43] \\
\hline 13 & Fructose & $\mathrm{FeCl}_{3}$ & $\mathrm{EtOH} /[\mathrm{Bmim}] \mathrm{Cl}$ & 100 & 4 & 30.1 & [44] \\
\hline 14 & Glucose & $\mathrm{AlCl}_{3}$ & $\mathrm{EtOH} /$ water & 160 & 0.25 & 33 & [45] \\
\hline 15 & HMF & $\mathrm{AlCl}_{3}$ & $\mathrm{EtOH}$ & 100 & 5 & 92.9 & [46] \\
\hline 16 & Fructose & $\mathrm{AlCl}_{3}$ & $\mathrm{EtOH}$ & 100 & 11 & 71.2 & [46] \\
\hline 17 & Inulin & $\mathrm{AlCl}_{3}$ & $\mathrm{EtOH}$ & 100 & 11 & 58.2 & [46] \\
\hline 18 & Glucose & $\mathrm{AlCl}_{3}$ & $\mathrm{EtOH}$ & 100 & 11 & 38.4 & [46] \\
\hline 19 & Starch & $\mathrm{AlCl}_{3}$ & $\mathrm{EtOH}$ & 100 & 11 & 27.2 & [46] \\
\hline 20 & Fructose & $\mathrm{AlCl}_{3} \cdot 6 \mathrm{H}_{2} \mathrm{O} / \mathrm{BF}_{3} \cdot(\mathrm{Et})_{2} \mathrm{O}$ & $\mathrm{EtOH}$ & 110 & 3 & 55 & {$[47]$} \\
\hline 21 & Fructose & $\mathrm{AlCl}_{3} \cdot 6 \mathrm{H}_{2} \mathrm{O} / \mathrm{B}(\mathrm{OH})_{3}$ & $\mathrm{EtOH}$ & 110 & 3 & 22 & {$[47]$} \\
\hline 22 & Fructose & $\mathrm{AlCl}_{3} \cdot 6 \mathrm{H}_{2} \mathrm{O} / \mathrm{NaF}$ & $\mathrm{EtOH}$ & 110 & 3 & 25.1 & [47] \\
\hline 23 & Fructose & $\mathrm{AlCl}_{3} \cdot 6 \mathrm{H}_{2} \mathrm{O} / \mathrm{NaCl}$ & $\mathrm{EtOH}$ & 110 & 3 & 28.9 & [47] \\
\hline 24 & Fructose & $\mathrm{AlCl}_{3} \cdot 6 \mathrm{H}_{2} \mathrm{O} / \mathrm{NaBr}$ & $\mathrm{EtOH}$ & 110 & 3 & 26.3 & [47] \\
\hline 25 & Sucrose & $\mathrm{AlCl}_{3} \cdot 6 \mathrm{H}_{2} \mathrm{O} / \mathrm{BF}_{3} \cdot(\mathrm{Et})_{2} \mathrm{O}$ & $\mathrm{EtOH}$ & 110 & 3 & 23.9 & [47] \\
\hline 26 & Inulin & $\mathrm{AlCl}_{3} \cdot 6 \mathrm{H}_{2} \mathrm{O} / \mathrm{BF}_{3} \cdot(\mathrm{Et})_{2} \mathrm{O}$ & $\mathrm{EtOH}$ & 110 & 3 & 45.4 & {$[47]$} \\
\hline
\end{tabular}


[43]. They found that $\mathrm{LiCl}, \mathrm{NaCl}$, and $\mathrm{FeCl}_{2} \cdot 4 \mathrm{H}_{2} \mathrm{O}$ had no catalytic activity for fructose and the amount of EMF was almost not detected. However, 23, 28 and 33\% yield of EMF could be detected from $\mathrm{SnCl}_{4} \cdot 5 \mathrm{H}_{2} \mathrm{O}, \mathrm{FeCl}_{3}$, and $\mathrm{CrCl}_{3} \cdot 6 \mathrm{H}_{2} \mathrm{O}$, respectively. Zhou et al. [44] also found that $\mathrm{FeCl}_{3}$ acted as the catalyst could reach acceptable EMF yield. In another case, $\mathrm{AlCl}_{3}$ was introduced into EMF production from glucose in an ethanol-water mixture, it was beneficial to prepare furan products (included HMF and EMF) with 57\% yield in short reaction time (15 min). Unfortunately, only 33\% EMF yield was detected, indicating its selectivity for EMF production was not satisfactory [45]. Inspired by this, Liu et al. [46] further studied the conversion of glucose-to-EMF over $\mathrm{AlCl}_{3}$ as a homogeneous catalyst in ethanol medium, and the reactions were conducted at $100^{\circ} \mathrm{C}$ for $11 \mathrm{~h}$. However, the improvement of the EMF amount was not significant by this modification and EMF yield only increased to $38.4 \%$. It was worth noticing that $\mathrm{AlCl}_{3}$ had excellent catalytic activity and the yield of HMF etherification to EMF was $92.9 \%$. At the same time, $\mathrm{AlCl}_{3}$ also showed great catalytic activity for other carbohydrates, 71.2, 58.2 and 27.2\% EMF yields could be reached from fructose, inulin, and starch, respectively. The combinations of $\mathrm{AlCl}_{3}$ and $\mathrm{BF}_{3} \cdot(\mathrm{Et})_{2} \mathrm{O}, \mathrm{B}(\mathrm{OH})_{3}$ or halide salts (i.e. $\mathrm{NaF}, \mathrm{NaCl}$, and $\mathrm{NaBr}$ ) were explored for the production of EMF from fructose by Jia et al. [47]. $\mathrm{AlCl}_{3} \cdot 6 \mathrm{H}_{2} \mathrm{O} /$ $\mathrm{BF}_{3} \cdot(\mathrm{Et})_{2} \mathrm{O}$ was the most advantageous combination for continuous dehydration and etherification of fructose, and it also had a good promoting effect on sucrose and inulin. Generally, the nature of metal chloride acted as Lewis acid is responsible for the good performance in the isomerization of glucose or glucose-based polymers. Unfortunately, the disadvantages of the metal chloride, such as the difficulty of separation and recycle, high price, instability, and toxicity, are not catered to the concept of green chemistry, which also limit the further exploration.

\section{Heterogeneous catalytic system}

Heterogeneous catalysts have some special properties in the reaction process, such as insoluble in reaction solvents, easy to separate, recyclable and high catalytic activity, which have attached many great attention than homogeneous catalysts [48]. Meanwhile, heterogeneous catalysts have superior controllability and can be used in the catalytic conversion of biomass due to adjustable specific surface area and acidic sites [49]. As listed in Table 3, heterogeneous catalysts for preparing EMF have been summarized.

\section{Zeolite catalysts}

Zeolite catalysts, as porous and green catalysts, play an important role in many fields, especially in the petrochemical industry [66, 67]. In recent years, Zeolite catalysts have also been applied to synthesize EMF. Che et al. [40] and Liu et al. [50] successively supported $\mathrm{H}_{4} \mathrm{SiW}_{12} \mathrm{O}_{40}$ and $\mathrm{H}_{3} \mathrm{PW}_{12} \mathrm{O}_{40}$ (HPW) on mesoporous MCM-41 with high catalytic activity, respectively. A series of mesoporous Al-MCM-41 molecular sieves with different $\mathrm{Si} / \mathrm{Al}$ ratios were synthesized by Lanzafame et al. (2011) [51], and the yield of EMF was up to 68\% from HMF. These catalysts had a high specific surface area (over $1000 \mathrm{~m}^{2} / \mathrm{g}$ ) and uniform mesoporous structure, and the introduction of $\mathrm{Al}^{3+}$ could obviously improve the catalytic activity and increase the selectivity of EMF synthesis. Bai et al. [52] reported a hierarchical lamellar multi-functional MFI-Sn/Al zeolite recently. The highlight is that the one-step crystallization zeolite was successfully synthesized with both Lewis acidic sites (Sn) and Brønsted acidic sites (Al-O(H)-Si), which enabled a three-step reaction cascade for the glucose to fructose (isomerization) over Lewis acidic sites and fructose to HMF (dehydration) and then HMF to EMF (etherification) in ethanal medium over Brønsted acidic sites. The EMF yield was $44 \%$ from glucose through cooperative catalysis.

\section{Heteropolyacid-based hybrids catalysts}

Heteropoly acids (HPA) catalysts are regarded as a kind of multi-functional catalysts due to considerably stable structure and adjustable acidity and alkalinity $[68,69]$. Li et al. [53] synthesized a series of nano-catalysts functionalized catalyst with basic amino acids and HPW as materials, the results showed that the most active catalyst combination consisted of lysine and HPW, the yields of EMF were 76.6, 58.5, 42.4, and 36.5\% from fructose, inulin, sorbose, and sucrose, respectively. HPA supported on K-10 clay was prepared for efficient synthesis of EMF from HMF and fructose by Zhang and co-authors [54], which made the EMF yield as high as 91.5 and $61.5 \%$, respectively. In addition, Zhang's group [55] also utilized the $\mathrm{Ag}_{1} \mathrm{H}_{2} \mathrm{PW}$ catalyst via an $\mathrm{Ag}^{+}$exchange between $\mathrm{HPW}$ and $\mathrm{AgNO}_{3}$. Their findings showed that the catalyst was most active when $\mathrm{Ag}^{+}$exchanged $1 \mathrm{H}^{+}$with HPW, and a high EMF yield of 88.7 and $69.5 \%$ could be reached when HMF and fructose were chosen as starting materials, respectively.

\section{Sulfonic acid-functionalized catalysts}

Not only do the solid acid catalysts supported acidic functional groups (such as $\mathrm{SO}_{3} \mathrm{H}$ group) have high catalytic performance, but also they are easy to separate and recover, non-corrosive equipment, and green environmental protection [70, 71]. Immobilization of sulfonic acid on the surface of Silica (Silica- $\mathrm{SO}_{3} \mathrm{H}$ ) was designed by Zhang's group [56], which could efficiently transform HMF, fructose, inulin, and sucrose utilized as feedstocks 
Table 3 Preparation of EMF from biomass by heterogeneous catalysts

\begin{tabular}{|c|c|c|c|c|c|c|c|}
\hline Entry & Feedstock & Catalyst & Solvent & Temp. $/{ }^{\circ} \mathrm{C}$ & Time/h & Yield/\% & Ref. \\
\hline 1 & HMF & 20\%HSiW/M-Ns & $\mathrm{EtOH}$ & 90 & 2 & 82.7 & {$[40]$} \\
\hline 2 & HMF & 40\%HSiW/M-Ns & $\mathrm{EtOH}$ & 90 & 2 & 85.8 & {$[40]$} \\
\hline 3 & HMF & 40\%HSiW/M-Ns & $\mathrm{EtOH}$ & 90 & 4 & 84.1 & {$[40]$} \\
\hline 4 & HMF & $60 \% \mathrm{HSiW} / \mathrm{M}-\mathrm{Ns}$ & $\mathrm{EtOH}$ & 90 & 2 & 83.2 & {$[40]$} \\
\hline 5 & HMF & 40 wt.\%MCM-41-HPW & $\mathrm{EtOH}$ & 100 & 12 & 83.4 & {$[50]$} \\
\hline 6 & Fructose & 40 wt.\%MCM-41-HPW & $\mathrm{EtOH}$ & 100 & 12 & 42.9 & {$[50]$} \\
\hline 7 & HMF & Al-MCM-41 (25) & $\mathrm{EtOH}$ & 140 & 5 & 67 & {$[51]$} \\
\hline 8 & HMF & Al-MCM-41 (50) & $\mathrm{EtOH}$ & 140 & 5 & 68 & {$[51]$} \\
\hline 9 & HMF & Al-MCM-41 (75) & $\mathrm{EtOH}$ & 140 & 5 & - & {$[51]$} \\
\hline 10 & Glucose & MFI-Sn/Al zeolite & $\mathrm{EtOH}$ & 140 & 9 & 44 & {$[52]$} \\
\hline 11 & Fructose & Lys/PW & EtOH/DMSO(7:3) & 200 & 15 & 76.6 & {$[53$} \\
\hline 12 & Inulin & Lys/PW & $\mathrm{EtOH} / \mathrm{DMSO}(7: 3)$ & 200 & 15 & 58.5 & {$[53]$} \\
\hline 13 & Sorbose & Lys/PW & $\mathrm{EtOH} / \mathrm{DMSO}(7: 3)$ & 200 & 15 & 42.4 & {$[53$} \\
\hline 14 & Sucrose & Lys/PW & EtOH/DMSO(7:3) & 200 & 15 & 36.5 & {$[53$} \\
\hline 15 & HMF & K-10 clay-HPW & $\mathrm{EtOH}$ & 100 & 10 & 91.5 & {$[54]$} \\
\hline 16 & Fructose & K-10 clay-HPW & $\mathrm{EtOH}$ & 100 & 10 & 61.5 & {$[54]$} \\
\hline 17 & HMF & $\mathrm{Ag}_{1} \mathrm{H}_{2} \mathrm{PW}$ & $\mathrm{EtOH}$ & 100 & 10 & 88.7 & {$[55]$} \\
\hline 18 & Fructose & $\mathrm{Ag}_{1} \mathrm{H}_{2} \mathrm{PW}$ & $\mathrm{EtOH}$ & 100 & 10 & 69.5 & {$[55$} \\
\hline 19 & HMF & Silica- $\mathrm{SO}_{3} \mathrm{H}$ & $\mathrm{EtOH}$ & 100 & 10 & 83.8 & {$[56]$} \\
\hline 20 & Fructose & Silica- $\mathrm{SO}_{3} \mathrm{H}$ & $\mathrm{EtOH}$ & 100 & 10 & 63.1 & {$[56]$} \\
\hline 21 & Inulin & Silica- $\mathrm{SO}_{3} \mathrm{H}$ & $\mathrm{EtOH}$ & 100 & 10 & 60.7 & {$[56$} \\
\hline 22 & HMF & $\mathrm{Fe}_{3} \mathrm{O}_{4} @ \mathrm{SiO}_{2}-\mathrm{SO}_{3} \mathrm{H}$ & $\mathrm{EtOH}$ & 100 & 10 & 89.3 & {$[57]$} \\
\hline 23 & Fructose & $\mathrm{Fe}_{3} \mathrm{O}_{4} @ \mathrm{SiO}_{2}-\mathrm{SO}_{3} \mathrm{H}$ & $\mathrm{EtOH}$ & 100 & 10 & 72.5 & {$[57]$} \\
\hline 24 & Inulin & $\mathrm{Fe}_{3} \mathrm{O}_{4} @ \mathrm{SiO}_{2}-\mathrm{SO}_{3} \mathrm{H}$ & $\mathrm{EtOH}$ & 100 & 10 & 63.3 & {$[57]$} \\
\hline 25 & HMF & $\mathrm{Fe}_{3} \mathrm{O}_{4} @ \mathrm{SiO}_{2}-\mathrm{SH}-\mathrm{Im}-\mathrm{HSO}_{4}$ & $\mathrm{EtOH}$ & 100 & 12 & 89.6 & {$[58$} \\
\hline 26 & Fructose & $\mathrm{Fe}_{3} \mathrm{O}_{4} @ \mathrm{SiO}_{2}-\mathrm{SH}-\mathrm{Im}-\mathrm{HSO}_{4}$ & $\mathrm{EtOH}$ & 120 & 24 & 60.4 & {$[58]$} \\
\hline 27 & Sucrose & $\mathrm{Fe}_{3} \mathrm{O}_{4} @ \mathrm{SiO}_{2}-\mathrm{SH}-\mathrm{Im}-\mathrm{HSO}_{4}$ & $\mathrm{EtOH}$ & 120 & 24 & 34.4 & {$[58$} \\
\hline 28 & Inulin & $\mathrm{Fe}_{3} \mathrm{O}_{4} @ \mathrm{SiO}_{2}-\mathrm{SH}-\mathrm{Im}-\mathrm{HSO}_{4}$ & $\mathrm{EtOH}$ & 120 & 24 & 56.1 & {$[58$} \\
\hline 29 & HMF & Cellulose sulfuric acid & $\mathrm{EtOH}$ & 100 & 10 & 84.4 & {$[59$} \\
\hline 30 & HMF & Cellulose sulfuric acid & $\mathrm{EtOH}$ & 100 & 10 & 72.5 & {$[59$} \\
\hline 31 & Fructose & Cellulose sulfuric acid & DMSO & 100 & 0.75 & $93.6^{a}$ & {$[59$} \\
\hline 32 & Fructose & $\mathrm{Ar}-\mathrm{CMSs}-\mathrm{SO}_{3} \mathrm{H}$ & $\mathrm{EtOH}$ & 100 & 12 & 68 & {$[60]$} \\
\hline 33 & HMF & $\mathrm{C}-\mathrm{SO}_{3} \mathrm{H}$ & $\mathrm{EtOH}$ & 100 & 6 & 71 & {$[61]$} \\
\hline 34 & HMF & $\mathrm{C}-\mathrm{SO}_{3} \mathrm{H}$ & $\mathrm{EtOH}$ & 140 & 8 & $81^{b}$ & {$[61]$} \\
\hline 35 & HMF & $30 \%$ Glu- $\mathrm{Fe}_{3} \mathrm{O}_{4}-\mathrm{SO}_{3} \mathrm{H}$ & $\mathrm{EtOH}$ & 80 & 2 & 92 & {$[62]$} \\
\hline 36 & Fructose & $50 \% \mathrm{Glu}-\mathrm{Fe}_{3} \mathrm{O}_{4}-\mathrm{SO}_{3} \mathrm{H}$ & $\mathrm{EtOH}$ & 80 & 24 & 81 & {$[62]$} \\
\hline 37 & Glucose & $50 \% \mathrm{Glu}-\mathrm{Fe}_{3} \mathrm{O}_{4}-\mathrm{SO}_{3} \mathrm{H}$ & $\mathrm{EtOH} / \mathrm{DMSO}$ & 140 & 48 & 27 & {$[62]$} \\
\hline 38 & Inulin & $50 \% \mathrm{Glu}-\mathrm{Fe}_{3} \mathrm{O}_{4}-\mathrm{SO}_{3} \mathrm{H}$ & $\mathrm{EtOH} / \mathrm{DMSO}$ & 100 & 24 & 85 & {$[62]$} \\
\hline 39 & Fructose & $\mathrm{Fe}_{3} \mathrm{O}_{4} @ \mathrm{C}-\mathrm{SO}_{3} \mathrm{H}$ & $\mathrm{EtOH} / \mathrm{DMSO}$ & 100 & 10 & 64 & {$[63]$} \\
\hline 40 & Fructose & $\mathrm{OMC}-\mathrm{SO}_{3} \mathrm{H}$ & $\mathrm{EtOH}$ & 140 & 24 & 55.7 & {$[64]$} \\
\hline 41 & Inulin & $\mathrm{OMC}^{-\mathrm{SO}_{3} \mathrm{H}}$ & $\mathrm{EtOH}$ & 140 & 24 & 53.6 & {$[64]$} \\
\hline 42 & Sucrose & $\mathrm{OMC}-\mathrm{SO}_{3} \mathrm{H}$ & $\mathrm{EtOH}$ & 140 & 24 & 26.8 & {$[64]$} \\
\hline 43 & HMF & $\mathrm{LS}-\mathrm{SO}_{3} \mathrm{H}$ & $\mathrm{EtOH}$ & 80 & 11 & 85.5 & {$[65]$} \\
\hline 44 & Fructose & $\mathrm{LS}-\mathrm{SO}_{3} \mathrm{H}$ & $\mathrm{EtOH}$ & 110 & 11 & 57.3 & {$[65$} \\
\hline 45 & Glucose & $\mathrm{LS}-\mathrm{SO}_{3} \mathrm{H}$ & $\mathrm{EtOH}$ & 110 & 15 & $77^{c}$ & {$[65$} \\
\hline 46 & Inulin & $\mathrm{LS} \mathrm{SO}_{3} \mathrm{H}$ & $\mathrm{EtOH}$ & 110 & 15 & 46.8 & {$[65]$} \\
\hline
\end{tabular}


into EMF while the yield of EMF was extremely low for glucose. The results showed that Silica- $\mathrm{SO}_{3} \mathrm{H}$ had little activity for the isomerization of glucose to fructose, but the catalyst was much conducive to the reaction of dehydration and etherification. Subsequently, the sulfonic acid functionalized catalyst was further improved by silica-encapsulated $\mathrm{Fe}_{3} \mathrm{O}_{4}$ nanoparticles supported sulfonic acid catalyst $\left(\mathrm{Fe}_{3} \mathrm{O}_{4} @ \mathrm{SiO}_{2}-\mathrm{SO}_{3} \mathrm{H}\right)$ [57]. In addition, magnetic material-supported polyionic liquid acid catalyst $\left(\mathrm{Fe}_{3} \mathrm{O}_{4} @ \mathrm{SiO}_{2}\right.$-SH-Im- $\left.\mathrm{HSO}_{4}\right)$ was also synthesized and it was used in the preparation of EMF by Zhang's group [58]. Not only do magnetically sulfonic acid functionalized catalysts have a great catalytic effect, but also they have excellent paramagnetism, resulting in the catalyst could be easily separated from the reaction mixture by magnetic separation.

Sulfonic acid functionalized catalysts supported carbon materials have attracted increasing attention, and they were prepared by incomplete carbonization of biomass and sulfonation treatment. Not only do catalysts have a similar catalytic effect with sulfuric acid, but also they have the advantages of good thermal stability and easy recycling and reuse. Cellulose sulfuric acid was prepared by direct sulfonation of cellulose with chlorosulfonic acid in organic solvents, and most of the $\mathrm{S}$ existed in the form of sulfonic groups with the content of $0.56 \mathrm{mmol} / \mathrm{g}$. The catalyst had an excellent catalytic activity for the synthesis of EMF in the ethanol system, it also could efficiently convert fructose to HMF (93.6\%) in the DMSO medium [59]. Zhao et al. [60] successfully fabricated sulfonic acid groups functionalized aromatic carbon microspheres $\left(\mathrm{Ar}-\mathrm{CMSs}-\mathrm{SO}_{3} \mathrm{H}\right)$ catalyst through waste camellia oleifera shells as carbon group. Due to Ar-CMSs- $\mathrm{SO}_{3} \mathrm{H}$ catalyst with abundant $-\mathrm{SO}_{3} \mathrm{H}$ groups and numerous spherical microstructure, it had an excellent activity for EMF preparation from HMF. MetalOrganic Frameworks (MOFs) were also applied as carbon groups for preparing the sulfonic acid functionalized catalyst, which exhibited highly considerable catalytic for etherification of HMF to EMF (71\%) or esterification of HMF to ethyl levulinate (81\%) in ethanol medium [61]. In addition, glucose [62], wheat straw [63], carbon nanomaterial [64], lignosulfonate [65] used as carbon groups were studied, respectively. The specific structures and chemical properties of carbonyl sulfonated solid acids were similar while the preparation methods and starting materials acted as carbon groups were different, which lead to a relatively high catalytic for the conversion of fructose-based carbohydrates to EMF. However, the catalysts generally could not effectively isomerize glucose to fructose.

\section{Other catalysts}

In addition, there were other heterogeneous catalysts for the preparation of EMF. Gupta and Saha [72] found a dual acidic titania carbocatalyst (Glu-TSOH-Ti) interplayed synergistically for EMF preparation by one-pot, 91 and 64\% EMF yield could be reached from HMF and fructose, respectively. Graphene oxide (GO) was discovered as a highly-efficient and stable catalyst through fructose-based carbohydrates to transform EMF [73]. GO performed great catalytic activity in the conversion of EMF for HMF etherification (92\%) in ethanol, and for fructose (71\%), sucrose $(34 \%)$ and inulin $(66 \%)$ in the ethanol-DMSO solvent system. Niobium molybdate, as a multilayer-like polyoxometalate with the varied metal components, was successfully designed by Yang et al. [74]. The record of EMF yield from HMF was broken with over 99\% due to the accurate regulation of the interlayer space of the $\mathrm{Nb}$ Mo oxides layer and the acid amount by the components of varied metal.

Although heterogeneous catalysts are convenient for separation and recovery and have relatively high catalytic efficiency for HMF and fructose-based carbohydrates, the efficiency is low. Meanwhile, some of them need to be calcined at a high temperature for regeneration, which is troublesome.

\section{Mixed-acid catalytic system}

In view of the unsatisfactory catalytic effect of a single acid, the mixed-acid catalytic system has been receiving the spotlight for the production of EMF from glucose or glucose-based polymers [75-77]. For example, a mixedacid system was explored via a combination of Amberlyst131 and zeolite Sn-BEA for EMF preparation from glucose, $31 \%$ EMF yield was obtained in ethanol for $24 \mathrm{~h}$ [25]. Xin et al. [78] have measured a moderate EMF yield of $30.6 \%$ from glucose catalyzed by the $\mathrm{AlCl}_{3}$ and PTSAPOM at $150^{\circ} \mathrm{C}$ for $30 \mathrm{~min}$. In addition, the one-pot twostep method was utilized to product EMF from glucose, which was carried out by adding H-USY for $5 \mathrm{~h}$ and followed by Amberlyst- 15 for $6 \mathrm{~h}$ [36]. Taking a clue from the above-mentioned design of catalyst, Peng's group proposed a mixed-acid system consisting of $\mathrm{Al}(\mathrm{OTf})_{3}$ and Amberlyst-15, an optimized EMF yield could be obtained in the ethanol-DMSO solvent system [79]. Presently, the mixed-acid catalytic system with both Lewis acid sites and Brønsted acid sites is a promising one for the ethanolysis of glucose-based substrates to EMF. The study on the synergistic effect between them will provide some valuable guidance for the design of catalysts in the future.

\section{Solvent system}

In addition to the catalysts, the reaction solvents also played an essential role in the process of EMF preparation [80, 81]. A good reaction solvent system could increase the amount of substrates and the yield of EMF to a certain extent. To study the effects of different solvents, the solvent systems used in the catalytic preparation of EMF were summarized in four categories: 1) single-phase solvent 
system, 2) biphasic solvent system, 3) ionic liquids system (ILs) and 4) deep eutectic solvents (DESs) system, which were listed in Table 4.

\section{Single-phase solvent system}

Ethanol was a common solvent for the production of EMF, but humins and other by-products were easily produced during the ethanolysis of carbohydrates [90]. When organic solvents such as n-hexane [42], DMSO [82], THF [83] and $\gamma$-valerolactone (GVL) [84] were used as cosolvents, the production of by-products could be effectively reduced and the EMF yield could be remarkably increased. Wang et al. [82] used "one-pot" method for EMF conversion from fructose, it was found that adding DMSO to ethanol system could increase the selectivity of the target product (EMF). With the increase of DMSO content in co-solvent, the yield of EMF increased from 28 to $64 \%$, which might be that DMSO could effectively inhibit the production of humins and the occurrence of side reaction (i.e. HMF rehydration). Meanwhile, they found that the yield of EMF began to decrease when the content of DMSO continued to increase, indicating that the etherification of HMF might be affected by the decrease of ethanol concentration in the reaction solvent system, and the reversible reaction was promoted at the same time. The author's group [83] studied the effect of THF on the conversion of corn stover and the reaction was optimized via response surface methodology. It was found that the introduction of THF could significantly increase the yield of EMF (21.8\%) in the ethanol/THF (1: 1) medium after 2.9

Table 4 Preparation of EMF from various solvents system

\begin{tabular}{|c|c|c|c|c|c|c|c|}
\hline Entry & Feedstock & Catalyst & Solvent & $\begin{array}{l}\text { Temp./ } \\
{ }^{\circ} \mathrm{C}\end{array}$ & Time/h & $\begin{array}{l}\text { Yield/ } \\
\%\end{array}$ & Ref. \\
\hline 1 & Fructose & $\mathrm{H}_{3} \mathrm{PW}_{12} \mathrm{O}_{40}$ & $\mathrm{EtOH} / \mathrm{DMSO}(7: 3)$ & 140 & $\begin{array}{l}130 \\
\min \end{array}$ & 64 & {$[82]$} \\
\hline 2 & Sucrose & $\mathrm{H}_{3} \mathrm{PW}_{12} \mathrm{O}_{40}$ & $\mathrm{EtOH} / \mathrm{DMSO}(7: 3)$ & 140 & $\begin{array}{l}130 \\
\min \end{array}$ & 28 & [82] \\
\hline 3 & Inulin & $\mathrm{H}_{3} \mathrm{PW}_{12} \mathrm{O}_{40}$ & $\mathrm{EtOH} / \mathrm{DMSO}(7: 3)$ & 140 & $\begin{array}{l}130 \\
\min \end{array}$ & 54 & [82] \\
\hline 4 & Corn stover & USY & $\mathrm{EtOH} / \mathrm{THF}(1: 1)$ & 168 & 2.9 & 21.8 & [83] \\
\hline 5 & Fructose & $\mathrm{MHGC}-\mathrm{SO}_{3} \mathrm{H}$ & $\mathrm{EtOH} / \mathrm{GVL}(2: 3)$ & 120 & 24 & 67.4 & [84] \\
\hline 6 & Glucose & $\mathrm{MHGC}-\mathrm{SO}_{3} \mathrm{H}$ & $\mathrm{EtOH} / \mathrm{GVL}(2: 3)$ & 120 & 24 & 3 & [84] \\
\hline 7 & Sucrose & $\mathrm{MHGC}-\mathrm{SO}_{3} \mathrm{H}$ & $\mathrm{EtOH} / \mathrm{GVL}(2: 3)$ & 120 & 24 & 33.1 & {$[84]$} \\
\hline 8 & Inulin & $\mathrm{MHGC}-\mathrm{SO}_{3} \mathrm{H}$ & $\mathrm{EtOH} / \mathrm{GVL}(2: 3)$ & 120 & 24 & 52.4 & {$[84]$} \\
\hline 9 & Glucose & $\mathrm{Zn}-\mathrm{SO}_{3} \mathrm{H}-\mathrm{GR}$-carbon & $\begin{array}{l}\text { ethanol/water/THF ( } 20 \mathrm{~mL}: 5 \mathrm{~mL}: 250 \\
\mathrm{mmol} \text { ) }\end{array}$ & 106 & 1.2 & 86.3 & [85] \\
\hline 10 & Fructose & {$[\mathrm{MIMBS}]_{3} \mathrm{PW}_{12} \mathrm{O}_{40}$} & $\mathrm{EtOH}$ & 90 & 24 & 90.5 & [14] \\
\hline 11 & HMF & {$[\mathrm{MIMBS}]_{3} \mathrm{PW}_{12} \mathrm{O}_{40}$} & $\mathrm{EtOH}$ & 70 & 24 & 90.7 & [14] \\
\hline 12 & HMF & {$[\mathrm{DMA}]^{+}\left[\mathrm{CH}_{3} \mathrm{SO}_{3}\right]^{-}$} & $\mathrm{EtOH}$ & 120 & 15 & 82.8 & [86] \\
\hline 13 & Fructose & {$[\mathrm{DMA}]^{+}\left[\mathrm{CH}_{3} \mathrm{SO}_{3}\right]^{-}$} & $\mathrm{EtOH}$ & 120 & 16 & 57.6 & {$[86]$} \\
\hline 14 & $\begin{array}{l}\text { Cellobiose } \\
\text { fibers }\end{array}$ & {$[\mathrm{DMA}]^{+}\left[\mathrm{CH}_{3} \mathrm{SO}_{3}\right]^{-}$} & $\mathrm{EtOH}$ & 120 & 20 & 19.8 & [86] \\
\hline 15 & Fructose & 1-Butyl-3-(3-sulfopropyl)-imidazolium chloride & $\mathrm{EtOH} /$ Hexanes & 100 & $80 \mathrm{~min}$ & 55 & [87] \\
\hline 16 & Fructose & $\begin{array}{l}\text { 1-Methyl-3-(3-sulfopropyl)-imidazolium } \\
\text { chloride }\end{array}$ & EtOH/Hexanes & 100 & $80 \mathrm{~min}$ & 54 & {$[87]$} \\
\hline 17 & Fructose & {$\left[\mathrm{C}_{4} \mathrm{mim}\right]\left[\mathrm{HSO}_{4}\right]$} & $\mathrm{EtOH}$ & 130 & 20 & 83 & [88] \\
\hline 18 & Fructose & {$\left[\mathrm{C}_{1} \mathrm{mim}\right]\left[\mathrm{HSO}_{4}\right]$} & $\mathrm{EtOH}$ & 130 & 15 & 77 & [88] \\
\hline 19 & Fructose & {$\left[\mathrm{C}_{2} \mathrm{mim}\right]\left[\mathrm{HSO}_{4}\right]$} & $\mathrm{EtOH}$ & 130 & 30 & 81 & [88] \\
\hline 20 & Inulin & {$[\mathrm{BMIM}]\left[\mathrm{HSO}_{4}\right]$} & $\mathrm{EtOH} /$ water & 130 & 30 & 77 & [89] \\
\hline 21 & Inulin & {$[\mathrm{EMIM}]\left[\mathrm{HSO}_{4}\right]$} & EtOH/water & 130 & 30 & 51 & [89] \\
\hline 22 & Inulin & {$[\mathrm{HMIM}]\left[\mathrm{HSO}_{4}\right]$} & EtOH/water & 130 & 30 & 63 & [89] \\
\hline 23 & Inulin & Amberlyst-15/ [BMIM][Cl] & $\mathrm{EtOH}$ & 130 & 30 & 49 & [89] \\
\hline 24 & Sucrose & {$[\mathrm{BMIM}]\left[\mathrm{HSO}_{4}\right]$} & $\mathrm{EtOH} /$ water & 130 & 30 & 43 & [89] \\
\hline 25 & Fructose & {$[\mathrm{BMIM}]\left[\mathrm{HSO}_{4}\right]$} & EtOH/water & 130 & 20 & 79 & [89] \\
\hline 26 & Glucose & {$[\mathrm{BMIM}]\left[\mathrm{HSO}_{4}\right]$} & EtOH/water & 130 & 20 & 8 & [89] \\
\hline
\end{tabular}


h. THF could provide a better hydrophobic environment and inhibit the formation of humins than ethanol. Although organic co-solvents can inhibit the formation of EMF degradation products to some extent, their solubility for carbohydrates is generally low, which limits the application of co-solvents in large-scale production of EMF. On the other hand, organic co-solvents usually have a higher boiling point, which brings great barriers to the separation and purification of EMF.

\section{Biphasic solvent system}

In order to overcome the shortcomings of single-phase solvent systems, biphasic solvent systems consisting of water and various organic solvents (such as benzene, methyl isobutyl ketone, and THF) have received increasing attention. Up to now, there are few reports about the application of the biphasic solvent system in the field of EMF preparation. Karnjanakom and Maneechakr (2019) [85] studied a novelty catalytic transformation of glucose in the ultrasound-assisted biphasic solvent system (ethanol-water-THF). Up to $86.3 \%$ of EMF yield could be obtained at $106^{\circ} \mathrm{C}$ after $72 \mathrm{~min}$, resulting in the easy production of EMF via isomerization, dehydration, and etherification in an excellent biphasic-heterogeneous reaction system. It was noteworthy that the biphasic solvent reaction system could improve the conversion of biomass-based carbohydrates, the selectivity and yield of EMF. As an efficient solvent system for the conversion of carbohydrates to EMF, the biphasic solvent system might be the first choice for the industrialization of EMF.

\section{Ionic liquids system}

Ionic liquids with excellent physicochemical properties have been employed for EMF preparation in recent years. For example, $N$-methylimidazole, 1,4-butane sultone and HPA were used to synthesize HPA-based IL hybrid catalyst [MIMBS $]_{3} \mathrm{PW}_{12} \mathrm{O}_{40}$ through two-step method, the EMF yield was up to $90.5 \%$ from fructose at $90{ }^{\circ} \mathrm{C}$ after $24 \mathrm{~h}$ [14]. De et al. introduced [DMA $]^{+}\left[\mathrm{CH}_{3} \mathrm{SO}_{3}\right]^{-}$as ILs to produce EMF [86], the yields were 82.8\% from HMF, 57.6\% from fructose and $19.8 \%$ from cellobiose fibers, respectively. Functional ionic liquids containing sulfonic acid groups were designed for conversion of fructose into EMF by Kraus and Guney [87]. The yield of EMF was 55 and 54\% over 1-butyl-3(3-sulfopropyl)-imidazolium chloride and 1methyl-3-(3-sulfopropyl)-imidazolium chloride, respectively. To our happiness, the catalytic performance of tailored ILs did not decrease significantly after 5 recycles. A series of ionic liquids (hydrogen sulfate ILs, acetate ILs, diethylphosphate ILs, dimethylphosphate ILs and chloride ILs) were investigated by Qi and co-authors [88], and the results showed that $\left[\mathrm{C}_{4} \mathrm{mim}\right]\left[\mathrm{HSO}_{4}\right]$ was more conductive to EMF preparation in ethanol medium. The yield of EMF was up to $83 \%$ in a short time $(20 \mathrm{~min})$, which might be a result of the acidity of anion and a stabilizing hydrogen bond between HMF and ILs. Based on that, other types of hydrogen sulfate groups in the ionic liquids ([BMIM][HSO4], $[\mathrm{EMIM}]\left[\mathrm{HSO}_{4}\right]$ and $[\mathrm{HMIM}]\left[\mathrm{HSO}_{4}\right]$ ) were also further explored for transform carbohydrates into EMF by Qi and coauthors [89]. It was found that glycoside bond was easy to break and the reaction intermediates were stable when $\left[\mathrm{HSO}_{4}\right]^{-}$group of ionic liquid used as catalyst, and yields of EMF were 79, 77 and 49\% from fructose, inulin and sucrose, respectively. The highly considerable EMF yield could be obtained in ILs solvent system while there are still some barriers, such as high boiling point, high price and difficulty to recycle. Consequently, it would be worthy indepth to develop a low boiling point, cheap and recyclable ionic liquid.

\section{Deep eutectic solvents (DESs) system}

DESs was known as a liquid mixture composed of the hydrogen-bonded donor (HBD, i.e. carboxylic acid, polyols) and hydrogen-bonded acceptor (HBA, i.e. choline salts), its solidification point was significantly lower than that of pure substances [91, 92]. Although the physical and chemical properties of DESs are similar to ionic liquids, they are regarded as a new green solvent due to its low toxicity, low-cost, environment-friendly and biodegradable [93, 94]. At present, there are few reports about the synthesis of EMF in the DESs system. The author's group [95] designed a novel DES system for the preparation of EMF by one-pot two-step method. Dehydration of carbohydrates to HMF was first conducted in the DESs system and then the generated HMF was extracted in situ into methyl cyanide $(\mathrm{MeCN})$. Ethanol and Amberlyst-15 were added into the obtained HMF solvent and then followed directly by the etherification. The two-phase solvent system (DESs/MeCN) showed excellent and stable recycling performance. After extracting and separating $\mathrm{HMF}, \mathrm{ChCl}$ could be directly used in the next recycling reaction. This method has highly industrial application value in preparing EMF from carbohydrates. Even though there are still limitations of the DESs system in converting biomass to EMF, it would be a trend to develop a highly active and easily recoverable catalyst for the preparation of EMF in the DESs system.

\section{Current challenges and future prospects}

The present review has outlined and discussed the latest achievements on the preparation of EMF from biomass in various solvents system over homogeneous, heterogeneous catalysts or mixed acid catalysts. Although many satisfactory results have been achieved, it should be noted that there are still many enormous challenges for the industrial production of EMF. In order to accelerate 
this process, some potential points should be addressed in future studies:

(1) The comprehensive utilization of lignocellulosic biomass raw. For the reaction system with a highly considerable yield of EMF, the feedstocks are mainly HMF or fructose with high cost, which is not conducive to the economic benefits of industrial production. Therefore, we should focus on developing the conversion of cheaper lignocellulosic biomass resources (i.e. forestry and agricultural wastes) into EMF, the pretreatment technology of raw materials should be applied as well.

(2) The innovative investigation of catalysts. The isomerization of glucose is the main bottleneck for the preparation of EMF. Theoretically, solid acid catalysts containing large specific surface area, proper pore size and adjustable acid sites of Brønsted and Lewis acid are conductive to EMF preparation from glucose-based biomass by a series of reactions of isomerization, dehydration and etherification. Thus, the multifunctional solid acid catalysts with specific porosity, magnetic components, non-precious metals and adjustable acidity are desirable for EMF synthesis.

(3) The strategic preparation of reaction mediums. It is well known that reaction mediums have an inestimable effect on improving the catalysts activity and reactants dissolution. Taking green chemistry, atomic economy and practical application into consideration, the ionic liquids and especially deep-eutectic solvents should be exploited with excellent properties such as biological degradability, low viscosity, low cost, strong solvency and so on. Presently, the published researches on the solvent system mainly focus on the single-phase solvent system, while the research publications on the two-phase solvent system, ionic liquid system, especially DESs system are not enough. Therefore, based on the available publications, the potential relationship between the catalyst system and the solvent system is unclear, which is still a challenge for a better design of the reaction system.

(4) The thorough exploration of mechanism. Up to now, the reaction mechanism is still not clear. The reaction mechanism is the foundation of catalyst optimization and solvent design, and it could provide theoretical evidence for it. Based on this, the reaction mechanism might make a breakthrough by computational simulations and theoretical calculations (i.e. molecular dynamics, quantum mechanics and density functional theory).

\section{Conclusions}

EMF is a promising transportation fuel and fuel additive. The biomass (especially low-cost and abundant agricultural and forestry wastes) is utilized for the preparation of EMF with very broad prospects. The innovative aspects of catalysts and solvents systems as well as mechanism should be invested twice as much effort according to current technologies and theories and then apply them in the preparation of EMF to clear up obstacles on the road of industrialized production, where amazing happens!

\section{Abbreviations}

BMF: 5-Bromomethylfurfural; CMF: 5-Chloromethylfurfural; DESs: Deep eutectic solvents; DMSO: Dimethyl sulfoxide; EG: Ethyl glucoside; EL: Ethyl levulinate; EMF: 5-Ethoxymethylfurfural; EtOH: Ethanol; GO: Graphene oxide; GVL: $\gamma$-valerolactone; HBA: Hydrogen-bonded acceptor; HBD: Hydrogenbonded donor; HMF: 5-Hydroxymethylfurfural; HPA: Heteropoly acids; HPW: $\mathrm{H}_{3} \mathrm{PW}_{12} \mathrm{O}_{40}$; ILs: Ionic liquids; MeCN: Methyl cyanide; MOFs: MetalOrganic Frameworks; THF: Tetrahydrofuran

\section{Acknowledgements}

We would like to acknowledge Dr. Jonathan Sperry from the Centre for Green Chemical Science, University of Auckland, New Zealand for his English refinery on this work.

Availability of date and materials

Not applicable.

\section{Authors' contributions}

$X Z$ and $B C$ conceived and designed this work; $B C$ drafted the paper; $X Z$, GY and $B C$ have revised the writing; All authors read and approved the final manuscript.

\section{Funding}

The authors gratefully acknowledge the financial support from the National Natural Science Foundation of China (Nos. 21978248, 21676223), the special fund for Fujian Ocean High-Tech Industry Development (No. FJHJF-L-2018-1), China, the Natural Science Foundation of Fujian Province of China (No.2019 J06005), and the Energy development Foundation of the College of Energy, Xiamen University (No. 2017NYFZ02).

\section{Competing interests}

The authors declare that they have no competing interests.

\section{Author details}

${ }^{1}$ College of Energy, Xiamen University, Xiamen 361102, China. ${ }^{2}$ Fujian Engineering and Research Centre of Clean and High-valued Technologies for Biomass, Xiamen Key Laboratory of Clean and High-valued Utilization for Biomass, Xiamen 361102, China. ${ }^{3}$ Henan Key Lab of Biomass Energy, Huayuan Road 29, Zhengzhou 450008, Henan, China.

Received: 8 October 2019 Accepted: 27 February 2020

Published online: 11 March 2020

\section{References}

1. Zhao H, Holladay JE, Brown H, Zhang ZC. Metal chlorides in ionic liquid solvents convert sugars to 5-hydroxymethylfurfural. Science. 2007;316(5831): 1597-600.

2. Kunkes EL, Simonetti DA, West RM, Serrano-Ruiz JC, Gartner CA, Dumesic JA Catalytic conversion of biomass to monofunctional hydrocarbons and targeted liquid-fuel classes. Science. 2008;322(5900):417-21.

3. Atsumi S, Hanai T, Liao JC. Non-fermentative pathways for synthesis of branched-chain higher alcohols as biofuels. Nature. 2008:451(7174):86-9.

4. Lee SY, Kim HU, Chae TU, Cho JS, Kim JW, Shin JH, et al. A comprehensive metabolic map for production of bio-based chemicals. Nat Catal. 2019;2(1): 18-33.

5. Morales G, Paniagua M, Melero JA, Iglesias J. Efficient production of 5ethoxymethylfurfural from fructose by sulfonic mesostructured silica using DMSO as co-solvent. Catal Today. 2017;279:305-16.

6. Maneechakr P, Karnjanakom S. Selective conversion of fructose into 5 ethoxymethylfurfural over green catalyst. Res Chem Intermed. 2018;45(2): 743-56.

7. Viil I, Bredihhin A, Mäeorg U, Vares L. Preparation of potential biofuel 5ethoxymethylfurfural and other 5-alkoxymethylfurfurals in the presence of oil shale ash. RSC Adv. 2014;4(11):5689-93. 
8. Liu H, Tang X, Hao W, Zeng X, Sun Y, Lei T, et al. One-pot tandem conversion of fructose into biofuel components with in-situ generated catalyst system. J Energy Chem. 2018;27(2):375-80.

9. Zhang J, Dong K, Luo W, Guan H. Catalytic upgrading of carbohydrates into 5-ethoxymethylfurfural using $\mathrm{SO}_{3} \mathrm{H}$ functionalized hyper-cross-linked polymer based carbonaceous materials. Fuel. 2018;234:664-73.

10. Mascal M, Nikitin EB. Direct, high-yield conversion of cellulose into biofuel. Angew Chem Int Ed Engl. 2008;47(41):7924-6.

11. Antunes $M M$, Russo PA, Wiper PV, Veiga JM, Pillinger $M$, Mafra $L$, et al. Sulfonated graphene oxide as effective catalyst for conversion of 5(hydroxymethyl)-2-furfural into biofuels. ChemSusChem. 2014;7(3):804-12.

12. Chen B, Xu G, Chang C, Zheng Z, Wang D, Zhang S, et al. Efficient one-pot production of biofuel 5-ethoxymethylfurfural from corn Stover: optimization and kinetics. Energy Fuel. 2019;33(5):4310-21.

13. Kumari PK, Rao BS, Padmakar D, Pasha N, Lingaiah N. Lewis acidity induced heteropoly tungustate catalysts for the synthesis of 5-ethoxymethyl furfural from fructose and 5-hydroxymethylfurfural. Mol Catal. 2018;448:108-15.

14. Liu B, Zhang Z, Deng K. Efficient one-pot synthesis of 5-(ethoxymethyl) furfural from fructose catalyzed by a novel solid catalyst. Ind Eng Chem Res. 2012;51(47):15331-6.

15. Wang S, Zhang Z, Liu B, Li J. Silica coated magnetic $\mathrm{Fe}_{3} \mathrm{O}_{4}$ nanoparticles supported phosphotungstic acid: a novel environmentally friendly catalyst for the synthesis of 5-ethoxymethylfurfural from 5-hydroxymethylfurfural and fructose. Catal Sci Technol. 2013;3(8):2104-12.

16. Russo PA, Antunes MM, Neves P, Wiper PV, Fazio E, Neri F, et al. Mesoporous carbon-silica solid acid catalysts for producing useful bioproducts within the sugar-platform of biorefineries. Green Chem. 2014;16(9): 4292-305.

17. Liu B, Gou Z, Liu A, Zhang Z. Synthesis of furan compounds from HMF and fructose catalyzed by aluminum-exchanged K-10 clay. J Ind Eng Chem. 2015;21:338-9.

18. Raveendra G, Rajasekhar A, Srinivas M, Sai Prasad PS, Lingaiah N. Selective etherification of hydroxymethylfurfural to biofuel additives over Cs containing silicotungstic acid catalysts. Appl Catal A: General. 2016;520:10513.

19. Li H, Zhang Q, Yang S. Catalytic cascade dehydration-etherification of fructose into 5-ethoxymethylfurfural with $\mathrm{SO}_{3} \mathrm{H}$-functionalized polymers. Int J Chem Eng. 2014;2014:1-7.

20. Sun Y, Zhang Q, Zhang P, Song D, Guo Y. Nitrogen-doped carbon-based acidic ionic liquid hollow nanospheres for efficient and selective conversion of fructose to 5 -ethoxymethylfurfural and ethyl levulinate. ACS Sustain Chem Eng. 2018;6(5):6771-82.

21. Bernardo JR, Oliveira MC, Fernandes $A C$. $\mathrm{HReO}_{4}$ as highly efficient and selective catalyst for the conversion of carbohydrates into value added chemicals. Mol Catal. 2019;465:87-94.

22. Kumar $\mathrm{A}$, Srivastava $\mathrm{R}$. $\mathrm{FeVO}_{4}$ decorated $-\mathrm{SO}_{3} \mathrm{H}$ functionalized polyaniline for direct conversion of sucrose to 2,5-diformylfuran \& 5-ethoxymethylfurfural and selective oxidation reaction. Mol Catal. 2019;465:68-79.

23. Zhang L, Zhu Y, Tian L, He Y, Wang H, Deng F. One-pot alcoholysis of carbohydrates to biofuel 5-ethoxymethylfufural and 5-methoxymethylfufural via a sulfonic porous polymer. Fuel Process Technol. 2019;193:39-47.

24. Chen T, Peng L, Yu X, He L. Magnetically recyclable cellulose-derived carbonaceous solid acid catalyzed the biofuel 5-ethoxymethylfurfural synthesis from renewable carbohydrates. Fuel. 2018;219:344-52.

25. Lew CM, Rajabbeigi N, Tsapatsis M. One-pot synthesis of 5-(ethoxymethyl) furfural from glucose using Sn-BEA and amberlyst catalysts. Ind Eng Chem Res. 2012:51(14):5364-6.

26. Yang Y, Abu-Omar MM, Hu C. Heteropolyacid catalyzed conversion of fructose, sucrose, and inulin to 5-ethoxymethylfurfural, a liquid biofuel candidate. Appl Energy. 2012;99:80-4.

27. Liu X, Li H, Pan H, Zhang H, Huang S, Yang K, et al. Efficient catalytic conversion of carbohydrates into 5-ethoxymethylfurfural over MIL-101 based sulfated porous coordination polymers. J Energy Chem. 2016;25(3): 523-30.

28. Xu G, Chen B, Zhang S, Wang D, Li K. Process optimization on 5ethoxymethylfurfural production from cellulose catalyzed by extremely low acid in one-pot reaction. Nongye Gongcheng Xuebao. 2018;34(19):225-31.

29. Tan J, Liu Q, Chen L, Wang T, Ma L, Chen G. Efficient production of ethyl levulinate from cassava over $\mathrm{Al}_{2}\left(\mathrm{SO}_{4}\right)_{3}$ catalyst in ethanol-water system. J Energy Chem. 2017;26(1):115-20.
30. Dutta S, De S, Alam Ml, Abu-Omar MM, Saha B. Direct conversion of cellulose and lignocellulosic biomass into chemicals and biofuel with metal chloride catalysts. J Catal. 2012;288:8-15.

31. Lanzafame P, Papanikolaou G, Perathoner S, Centi G, Migliori M, Catizzone E, et al. Direct versus acetalization routes in the reaction network of catalytic HMF etherification. Catal Sci Technol. 2018;8(5):1304-13.

32. Agarwal B, Kailasam K, Sangwan RS, Elumalai S. Traversing the history of solid catalysts for heterogeneous synthesis of 5-hydroxymethylfurfural from carbohydrate sugars: a review. Renewable and Sustainable Energy Rev. 2018:82:2408-25.

33. Zhou P, Zhang Z. One-pot catalytic conversion of carbohydrates into furfural and 5-hydroxymethylfurfural. Catal Sci Technol. 2016;6(11):3694-712.

34. Mika LT, Csefalvay E, Nemeth A. Catalytic conversion of carbohydrates to initial platform chemicals: chemistry and sustainability. Chem Rev. 2018; 118(2):505-613.

35. Bredihhin A, Maeorg U, Vares L. Evaluation of carbohydrates and lignocellulosic biomass from different wood species as raw material for the synthesis of 5-bromomethyfurfural. Carbohydr Res. 2013;375:63-7.

36. Li H, Saravanamurugan S, Yang S, Riisager A. Direct transformation of carbohydrates to the biofuel 5-ethoxymethylfurfural by solid acid catalysts. Green Chem. 2016:18(3):726-34.

37. Langeslay RR, Kaphan DM, Marshall CL, Stair PC, Sattelberger AP, Delferro M. Catalytic applications of vanadium: a mechanistic perspective. Chem Rev. 2019;119(4):2128-91

38. Balakrishnan M, Sacia ER, Bell AT. Etherification and reductive etherification of 5-(hydroxymethyl)furfural: 5-(alkoxymethyl) furfurals and 2,5-bis (alkoxymethyl) furans as potential bio-diesel candidates. Green Chem. 2012; 14(6):1626-34

39. Lai L, Zhang Y. The production of 5-hydroxymethylfurfural from fructose in isopropyl alcohol: a green and efficient system. ChemSusChem. 2011;4(12): $1745-8$.

40. Che P, Lu F, Zhang J, Huang Y, Nie X, Gao J, et al. Catalytic selective etherification of hydroxyl groups in 5-hydroxymethylfurfural over $\mathrm{H}_{4} \mathrm{SiW}_{12} \mathrm{O}_{40} / \mathrm{MCM}-41$ nanospheres for liquid fuel production. Bioresour Technol. 2012;119:433-6.

41. Flannelly T, Dooley S, Leahy JJ. Reaction pathway analysis of ethyl levulinate and 5-ethoxymethylfurfural from D-fructose acid hydrolysis in ethanol. Energy Fuel. 2015;29(11):7554-65.

42. Xu G, Chen B, Zheng Z, Li K, Tao H. One-pot ethanolysis of carbohydrates to promising biofuels: 5 -ethoxymethylfurfural and ethyl levulinate. Asia-Pacific 」 Chem Eng. 2017;12(4):527-35.

43. Liu J, Tang Y, Wu K, Bi C, Cui Q. Conversion of fructose into 5hydroxymethylfurfural (HMF) and its derivatives promoted by inorganic salt in alcohol. Carbohydr Res. 2012;350:20-4.

44. Zhou X, Zhang Z, Liu B, Zhou Q, Wang S, Deng K. Catalytic conversion of fructose into furans using $\mathrm{FeCl}_{3}$ as catalyst. J Ind and Eng Chem. 2014;20(2): 644-9.

45. Yang Y, Hu C, Abu-Omar MM. Conversion of glucose into furans in the presence of $\mathrm{AlCl}_{3}$ in an ethanol-water solvent system. Bioresour Technol. 2012;116:190-4

46. Liu B, Zhang Z, Huang K, Fang Z. Efficient conversion of carbohydrates into 5-ethoxymethylfurfural in ethanol catalyzed by $\mathrm{AlCl}_{3}$. Fuel. 2013;113:625-31.

47. Jia X, Ma J, Che P, Lu F, Miao H, Gao J, et al. Direct conversion of fructosebased carbohydrates to 5-ethoxymethylfurfural catalyzed by $\mathrm{AlCl}_{3} \cdot 6 \mathrm{H}_{2} \mathrm{O} /$ $\mathrm{BF}_{3}$.(et) $2 \mathrm{O}$ in ethanol. J Energy Chem. 2013:22:93-7.

48. Dhakshinamoorthy A, Li Z, Garcia H. Catalysis and photocatalysis by metal organic frameworks. Chem Soc Rev. 2018:47(22):8134-72.

49. Gomez E, Yan B, Kattel S, Chen JG. Carbon dioxide reduction in tandem with light-alkane dehydrogenation. Nature Reviews Chemistry. 2019;3:63849.

50. Liu A, Zhang Z, Fang Z, Liu B, Huang K. Synthesis of 5-ethoxymethylfurfural from 5-hydroxymethylfurfural and fructose in ethanol catalyzed by MCM-41 supported phosphotungstic acid. J Ind Eng Chem. 2014;20(4):1977-84.

51. Lanzafame P, Temi DM, Perathoner S, Centi G, Macario A, Aloise A, et al. Etherification of 5-hydroxymethyl-2-furfural (HMF) with ethanol to biodiesel components using mesoporous solid acidic catalysts. Catal Today. 2011; 175(1):435-41.

52. Bai Y, Wei L, Yang M, Chen H, Holdren S, Zhu G, et al. Three-step cascade over a single catalyst: synthesis of 5-(ethoxymethyl) furfural from glucose over a hierarchical lamellar multi-functional zeolite catalyst. J Mater Chem A. 2018;6(17):7693-705 
53. Li H, Govind KS, Kotni R, Shunmugavel S, Riisager A, Yang S. Direct catalytic transformation of carbohydrates into 5-ethoxymethylfurfural with acid-base bifunctional hybrid nanospheres. Energy Convers Manag. 2014;88:1245-51.

54. Liu A, Liu B, Wang Y, Ren R, Zhang Z. Efficient one-pot synthesis of 5ethoxymethylfurfural from fructose catalyzed by heteropolyacid supported on K-10 clay. Fuel. 2014;117:68-73.

55. Ren Y, Liu B, Zhang Z, Lin J. Silver-exchanged heteropolyacid catalyst $\left(\mathrm{Ag}_{1} \mathrm{H}_{2} \mathrm{PW}\right)$ : an efficient heterogeneous catalyst for the synthesis of 5ethoxymethylfurfural from 5-hydroxymethylfurfural and fructose. J Ind Eng Chem. 2015:21:1127-31.

56. Liu B, Zhang Z. One-pot conversion of carbohydrates into 5ethoxymethylfurfural and ethyl d-glucopyranoside in ethanol catalyzed by a silica supported sulfonic acid catalyst. RSC Adv. 2013;3(30):12313-9.

57. Zhang Z, Wang Y, Fang Z, Liu B. Synthesis of 5-ethoxymethylfurfural from fructose and inulin catalyzed by a magnetically recoverable acid catalyst. ChemPlusChem. 2014;79(2):233-40.

58. Yin S, Sun J, Liu B, Zhang Z. Magnetic material grafted cross-linked imidazolium based polyionic liquids: an efficient acid catalyst for the synthesis of promising liquid fuel 5-ethoxymethylfurfural from carbohydrates. J Mater Chem A 2015;3(9):4992-9.

59. Liu B, Zhang Z, Huang K. Cellulose sulfuric acid as a bio-supported and recyclable solid acid catalyst for the synthesis of 5-hydroxymethylfurfura and 5-ethoxymethylfurfural from fructose. Cellulose. 2013;20(4):2081-9.

60. Zhao K, Liu S, Li K, Hu Z, Yuan Y, Yan L, et al. Fabrication of $-\mathrm{SO}_{3} \mathrm{H}$ functionalized aromatic carbon microspheres directly from waste Camellia oleifera shells and their application on heterogeneous acid catalysis. Mol Catal. 2017:433:193-201.

61. Wang Z, Chen Q. Variations of major product derived from conversion of 5hydroxymethylfurfural over a modified MOFs-derived carbon material in response to reaction conditions. Nanomaterials (Basel). 2018:8(7):492.

62. Thombal RS, Jadhav VH. Application of glucose derived magnetic solid acid for etherification of 5-HMF to 5-EMF, dehydration of sorbitol to isosorbide, and esterification of fatty acids. Tetrahedron Lett. 2016;57(39):4398-400.

63. Yao Y, Gu Z, Wang Y, Wang HJ, Li W. Magnetically-recoverable carbonaceous material: an efficient catalyst for the synthesis of 5hydroxymethylfurfural and 5-ethoxymethylfurfural from carbohydrates. Russ J Gen Chem. 2016;86(7):1698-704

64. Wang J, Zhang Z, Jin S, Shen X. Efficient conversion of carbohydrates into 5hydroxylmethylfurfan and 5-ethoxymethylfurfural over sufonic acidfunctionalized mesoporous carbon catalyst. Fuel. 2017;192:102-7.

65. Yu X, Peng L, Gao X, He L, Chen K. One-step fabrication of carbonaceous solid acid derived from lignosulfonate for the synthesis of biobased furan derivatives. RSC Adv. 2018:8(28):15762-72.

66. Smit B, Maesen TL. Towards a molecular understanding of shape selectivity. Nature. 2008:451(7179):671-8

67. Shamzhy M, Opanasenko M, Concepcion P, Martinez A. New trends in tailoring active sites in zeolite-based catalysts. Chem Soc Rev. 2019;48(4): 1095-149.

68. Trombettoni $V$, Lanari $D$, Prinsen $P$, Luque $R$, Marrocchi A, Vaccaro L. Recent advances in sulfonated resin catalysts for efficient biodiesel and bio-derived additives production. Prog Energy Combust Sci. 2018;65:136-62.

69. Darabi Mahboub MJ, Dubois JL, Cavani F, Rostamizadeh M, Patience GS. Catalysis for the synthesis of methacrylic acid and methyl methacrylate. Chem Soc Rev. 2018;47(20):7703-38.

70. Doustkhah E, Lin J, Rostamnia S, Len C, Luque R, Luo X, et al. Development of sulfonic-acid-functionalized mesoporous materials: synthesis and catalytic applications. Chem Eur J. 2019;25(7):1614-35.

71. Mohammadi Ziarani G, Lashgari N, Badiei A. Sulfonic acid-functionalized mesoporous silica ( $\mathrm{SBA}-\mathrm{Pr}-\mathrm{SO}_{3} \mathrm{H}$ ) as solid acid catalyst in organic reactions. J Mol Catal A Chem. 2015;397:166-91.

72. Gupta D, Saha B. Dual acidic titania carbocatalyst for cascade reaction of sugar to etherified fuel additives. Catal Commun. 2018;110:46-50.

73. Wang H, Deng T, Wang Y, Cui X, Qi Y, Mu X, et al. Graphene oxide as a facile acid catalyst for the one-pot conversion of carbohydrates into 5ethoxymethylfurfural. Green Chem. 2013;15(9):2379-83.

74. Yang F, Tang J, Ou R, Guo Z, Gao S, Wang Y, et al. Fully catalytic upgrading synthesis of 5-Ethoxymethylfurfural from biomass-derived 5 Hydroxymethylfurfural over recyclable layered-niobium-molybdate solid acid. Appl Catal B. 2019;256:117786.

75. Guo H, Duereh A, Hiraga Y, Qi X, Smith RL. Mechanism of glucose conversion into 5-ethoxymethylfurfural in ethanol with hydrogen sulfate ionic liquid additives and a Lewis acid catalyst. Energy Fuel. 2018;32(8): $8411-9$.

76. Chang C, Xu G, Zhu W, Bai J, Fang S. One-pot production of a liquid biofuel candidate_-ethyl levulinate from glucose and furfural residues using a combination of extremely low sulfuric acid and zeolite USY. Fuel. 2015;140: 365-70.

77. Xu G, Chang C, Zhu W, Li B, Ma X, Du F. A comparative study on direct production of ethyl levulinate from glucose in ethanol media catalysed by different acid catalysts. Chem Pap. 2013;67(11):1355-63.

78. Xin H, Zhang T, Li W, Su M, Li S, Shao Q, et al. Dehydration of glucose to 5hydroxymethylfurfural and 5-ethoxymethylfurfural by combining Lewis and Brønsted acid. RSC Adv. 2017;7(66):41546-51.

79. Yu X, Gao X, Peng L, He L, Zhang J. Intensified 5-Ethoxymethylfurfural production from biomass components over aluminum-based mixed-acid catalyst in co-solvent medium. ChemistrySelect. 2018;3(47):13391-9.

80. Tang X, Zuo M, Li Z, Liu H, Xiong C, Zeng X, et al. Green processing of lignocellulosic biomass and its derivatives in deep eutectic solvents. ChemSusChem. 2017;10(13):2696-706.

81. Hu L, Xu J, Zhou S, He A, Tang X, Lin L, et al. Catalytic advances in the production and application of biomass-derived 2,5-dihydroxymethylfuran. ACS Catal. 2018;8(4):2959-80

82. Wang $H$, Deng $T$, Wang $Y$, Qi $Y$, Hou $X$, Zhu Y. Efficient catalytic system for the conversion of fructose into 5-ethoxymethylfurfural. Bioresour Technol. 2013;136:394-400.

83. Chen B, Xu G, Zheng Z, Wang D, Zou C, Chang C. Efficient conversion of corn Stover into 5-ethoxymethylfurfural catalyzed by zeolite USY in ethanol/ THF medium. Ind Crop Prod. 2019;129:503-11.

84. Bai Y, Su S, Wang S, Wang B, Sun R, Song G, et al. Catalytic conversion of carbohydrates into 5-ethoxymethylfurfural by a magnetic solid acid using $\gamma^{-}$ valerolactone as a co-solvent. Energy Technol. 2018;6(10):1951-8.

85. Karnjanakom S, Maneechakr P. Designs of linear-quadratic regression models for facile conversion of carbohydrate into high value (5(ethoxymethyl)furan-2-carboxaldehyde) fuel chemical. Energy Convers Manag. 2019;196:410-7.

86. De S, Dutta S, Saha B. One-pot conversions of lignocellulosic and algal biomass into liquid fuels. ChemSusChem. 2012;5(9):1826-33.

87. Kraus GA, Guney T. A direct synthesis of 5-alkoxymethylfurfural ethers from fructose via sulfonic acid-functionalized ionic liquids. Green Chem. 2012; 14(6):1593-6.

88. Guo H, Qi X, Hiraga Y, Aida TM, Smith RL. Efficient conversion of fructose into 5-ethoxymethylfurfural with hydrogen sulfate ionic liquids as co-solvent and catalyst. Chem Eng J. 2017;314:508-14.

89. Guo H, Duereh A, Hiraga Y, Aida TM, Qi X, Smith RL. Perfect recycle and mechanistic role of hydrogen sulfate ionic liquids as additive in ethanol for efficient conversion of carbohydrates into 5-ethoxymethylfurfural. Chem Eng J. 2017;323:287-94.

90. Zhong R, Yu F, Schutyser W, Liao Y, de Clippel F, Peng L, et al. Acidic mesostructured silica-carbon nanocomposite catalysts for biofuels and chemicals synthesis from sugars in alcoholic solutions. Appl Catal B. 2017; 206:74-88.

91. Carriazo D, Serrano MC, Gutierrez MC, Ferrer ML, del Monte F. Deep-eutectic solvents playing multiple roles in the synthesis of polymers and related materials. Chem Soc Rev. 2012:41(14):4996-5014.

92. Zuo M, Li Z, Jiang $Y$, Tang $X$, Zeng $X$, Sun $Y$, et al. Green catalytic conversion of bio-based sugars to 5-chloromethyl furfural in deep eutectic solvent, catalyzed by metal chlorides. RSC Adv. 2016;6(32):27004-7.

93. Zuo M, Le K, Li Z, Jiang $Y$, Zeng $X$, Tang $X$, et al. Green process for production of 5-hydroxymethylfurfural from carbohydrates with high purity in deep eutectic solvents. Ind Crop Prod. 2017:99:1-6.

94. Smith EL, Abbott AP, Ryder KS. Deep eutectic solvents (DESs) and their applications. Chem Rev. 2014;114(21):11060-82.

95. Zuo M, Le K, Feng Y, Xiong C, Li Z, Zeng X, et al. An effective pathway for converting carbohydrates to biofuel 5-ethoxymethylfurfural via 5hydroxymethylfurfural with deep eutectic solvents (DESs). Ind Crop Prod. 2018:112:18-23.

\section{Publisher's Note}

Springer Nature remains neutral with regard to jurisdictional claims in published maps and institutional affiliations. 